\title{
Study of Cyclopropanation Reactions Using Co(II)Tetraphenylporphyrin as Catalysts for Preparation of Rotaxanes
}

\author{
Kamila C. Santos (IC), Jackson D. M. Júnior (PQ)
}

\begin{abstract}
Porphyrins are organic molecules that show potential to several applications, such as catalysis. In this work, we synthetized a porphyrin catalyst that is composed of tetraphenylporphyrin with a cobalt ion in its interior for future investigation in cyclopropanation reactions for the synthesis of supramolecular systems such as rotaxanes and catenanes. Analysis of $1 \mathrm{H}$ NMR and UV-Vis absorption spectroscopies have shown that the reactions of synthesis and metalation were achieved with success.
\end{abstract}

Key words: porphyrin, cyclopropanation, biomimetics.

\section{Introduction}

Porphyrins are organic molecules with a tetra pyrrole macrocycle. It has an empty space at its center that allows the insertion of metallic ions, such as cobalt, iron, and nickel, among others. Tetraphenylporphyrin (TPP) is a compound of the porphyrin family that has four phenyl groups at 5, 10,15 and 20 positions of the porphyrin core. The present work describes the synthesis and partial characterization of CoTPP. The CoTPP catalytic properties and its ability to organize molecular components into rotaxanes supramolecular structures are under investigation in our labs.

\section{Results and Discussion}

For the synthesis of tetraphenylporphyrin (TPP) it was used the procedure described by Lindsey[1] et al., whereas the method described by Rothemund and Menotti[2] was used to insert the cobalt ion into the porphyrin core. UV-Vis absorption spectroscopy (Figure 1) showed a hypsochromic shift for the CoTPP Soret band $(410 \mathrm{~nm})$ when compared with that of the TPP $(417 \mathrm{~nm})$, suggesting the insertion of the $\mathrm{Co}$ (II) ion into the porphyrin core. $1 \mathrm{H}$ NMR of the TPP revealed a singlet at $8.84 \mathrm{ppm}$ along with two dublets at 8.82 and $7.77 \mathrm{ppm}$, which corresponded to the pyrrolic and ortho, meta and para protons of the meso-phenyl rings, respectively. The $\mathrm{N}-\mathrm{H}$ inner protons resonated at $-2.80 \mathrm{ppm}$. Insertion of the $\mathrm{Co}$ (II) ion into the porphyrin core caused a down field shift of the protons resonances along with the disappearance of the signal of the inner protons at $2.80 \mathrm{ppm}$, confirming the CoTPP structure.

\section{Conclusions}

CoTPP has been successfully synthesized. The catalytic activity of CoTPP for cyclopropanation reactions under several different conditions has been investigated in our labs. The findings will be reported on due time.

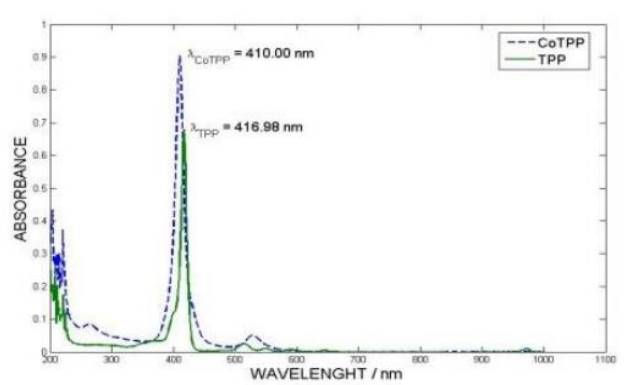

Figure 1. UV-Vis of CoTPP and TPP. Dichloromethane, room temperature.

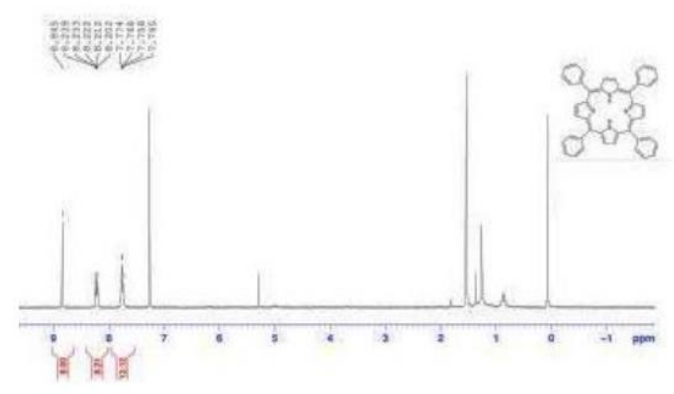

Figure 2. ${ }^{1} \mathrm{H}-\mathrm{NMR}$ of TPP. $\mathrm{CDCl}_{3}, 250 \mathrm{MHz}$, room temperature.

\section{Acknowledgement}

The authors acknowledge FAPESP and FUNCAMP for the financial support.

\footnotetext{
${ }^{1}$ Lindsey, J.S.; Hsu, H.C.; Schreiman, I.C.. Synthesis of Tetraphenylporphyrins Under Very Mild Conditions. Tetrahedron Letters, 1986, 27, 4969-4970.

${ }^{2}$ Rothemund, P.; Menotti, A.R.. Porphyrin Studies V - The Metal Complex Salts of $\alpha, \beta, \gamma, \delta$-Tetraphenylprphyrins. J. Am. Chem. Soc. 1948, 70, 1808-1812.
} 